\title{
Clinical Concepts in Oral and Maxillofacial Surgery and Novel Findings to the Field of Bone Regeneration
}

\author{
Annika Rosén and Rachael Sugars \\ Div of Oral and Maxillofacial Surgery and the Craniofacial Stem Cell Biology Group, \\ Div of Oral Biology, Dept. of Dental Medicine, Karolinska Institutet, Huddinge, \\ Sweden
}

\section{Introduction}

In an increasingly aging population, where aesthetics plays an important role in society, the loss of bone and teeth due to disease or trauma places a large burden on healthcare systems worldwide. It is estimated that more than 2.2 million grafting procedures are performed annually to repair bone defects in orthopedics, neurosurgery and dentistry (Giannoudis et al, 2005). Following surgical intervention the use of bone grafts / substitute materials or distraction osteogenesis (DO) for the expansion of the maxialla are current approaches to facilitate bone regeneration. What is regeneration and how is it defined? Regeneration can be defined as "the reproduction or reconstruction of a lost or injured part of the body in such a way that the architecture and function of the lost or injured tissues are completely restored" (Bosshardt et al, 2009), and as such it is necessary to consider the cells that are involved to produce the destroyed tissues, how can these cells be stimulated and is a space filler required to support the cells and to hold signaling molecules? Bone formation is a complex and dynamic process involving the interactions between cells and the surrounding milieu. Repair occurs before regeneration but where healing occurs first without restoration of function. The current chapter considers clinical approaches, cases and requirements for bone regeneration and brings it together with a biological perspective of the cellular and biomolecular interactions necessary to stimulate new bone formation. Given the increasing need for grafting procedures and the limitations to current grafting techniques the future applications of tissue engineering approaches are finally discussed.

\section{Clinical applications}

Reconstructive surgery for bony defects in the oral and maxillofacial region is a challenge. The gold standard for reconstructive surgery remains autogenous bone grafting that is osteoconductive and osteoinductive, and from an immunological point of view safe. Donor sites are available either intra- or extra orally. The intraoral harvesting sites are in the maxillary tuberosity and in the mandibular ramus, retromandibular area and the symphysis. The bone is often of cortical nature and the volume limited. Harvesting can be performed during local anesthesia often in combination with sedation. Harvesting bone 
from extra-oral sites is required when larger amounts are required. The iliac crest, tibia, costochondral bone or calvarium bone are common donor sites but general anesthesia and hospitalization of the patient is needed. The bone is both of cortical and cancellous/trabecular nature. When it is not possible to harvest bone due to the patient's medical history or limited resources, DO, a relatively new technique in the field of oral and maxillofacial surgery has been developed. This technique has also been useful in reconstructive surgery for genetic anomalies.

\subsection{Reconstruction of resorbed alveolar crests}

Edentulous severely resorbed maxillas are a major problem for patients when prosthodontic treatment and dental implants are necessary. The standard procedure installs the implants vertically in the alveolar crest with the implant totally covered by bone. The bone volume needs to be at least $10 \mathrm{~mm}$ in the vertical dimension and $4 \mathrm{~mm}$ in the horizontal aspect in the maxillary alveolar crest with this technique. In patients with less bone volume bone grafting is an alternative. Tilted implants were first presented by Mattsson and colleagues as an alternative method to bone grafting in severely resorbed alveolar crest, classes V and VI (Mattson et al 1999). The method of tilting the implants was used to reach the maximum length of the prosthodontic bridge. Recently, we presented a 10-year follow-up study on patients treated with this technique. The success rate was $97 \%$ (Rosén et al 2007). One reason for the high success rate could be attributed to the use of longer implants, thereby improving the anchorage in dense bone compared to conventional implant treatments. Another advantage was that the prosthetic construction could be more posteriorly directed in the arch and result in the equalisation of loading across the bridge. Krekmanow and collaborators have reported biomechanical measurements in tilting implants, which showed no negative effects on load distribution in the fixed prosthesis constructions (Krekmanow et al 2000). Furthermore, the method by which implants are tilted is relatively easy for the surgeon to perform and reduces the patient's treatment time (Fig. 1).

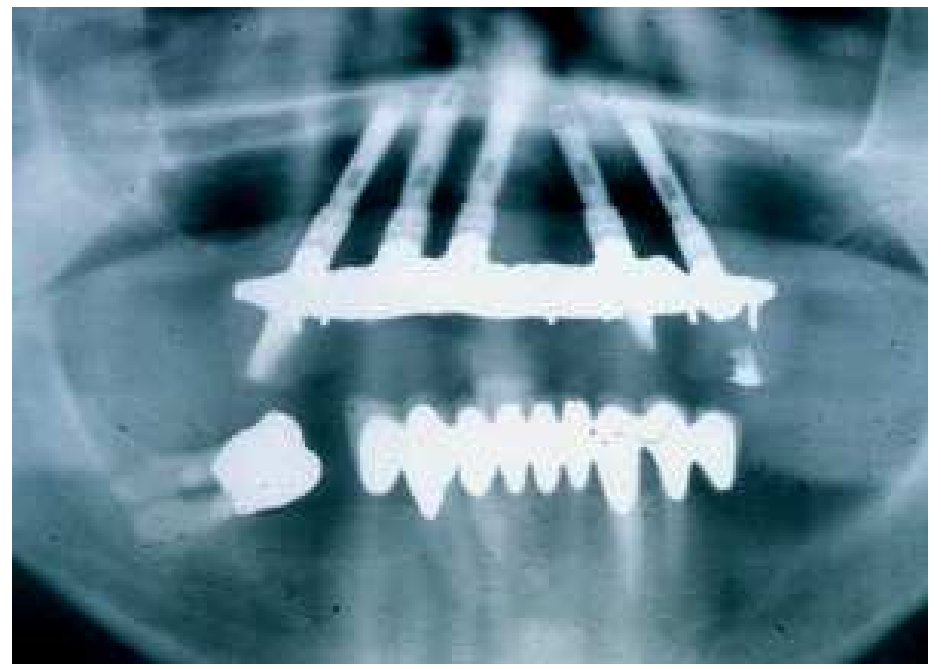

Fig. 1. X-ray, patient treated with tilted implants. 


\subsection{Sinus lift}

The first use of bone grafting to the maxillary sinus was presented in the 1960s by Boyne (Boyne 1969). He performed a so-called Caldwell-Luc opening, where a fenestration of the bone to the maxillary sinus made it possible to elevate the sinus membrane. Autogenous bone and marrow grafts were placed on the sinus floor. Approximately three months after surgery an increase of osseous tissue was seen. In a review by Triplett and collegues (Triplett et al 2000), they described the material choices for sinus augmentation, and concluded that autogenous bone was the best choice as it was osteoinductive, osteoconductive and contained osteoblasts and osteoprogenitor cells. The technique of sinus grafting has been used for placement of dental implants since then.

Sinus lift with an osteotom is another even easier technique to perform, when maxilla bone is moderately resorbed. The technique involves a series of increasingly wide osteotomes, which allows site preparation for the implant while also expanding the apical portion of the alveolus into the sinus. The elevated sinus membrane remains intact and bone forms beneath the elevated membrane, commonly 3-4 $\mathrm{mm}$ of floor height is effectively gained. The bone cells migrate from both the base of the sinus maxillaries and from the bone chip that is uplifted into the sinus. From the start the bone height has to be at least $4 \mathrm{~mm}$ so that a 9 or $11 \mathrm{~mm}$ implant can be installed. The concept of "tenting-up" the membrane in both the sinus floor and the nasal floor was first described by Brånemark (Brånemark et al 1984).

A 2-3-year follow-up study evaluated the survival rate of dental implants placed in partially or totally edentulous maxillae, with moderately resorbed bone (Dabirian and Rosén 2004). The implants were placed directly in the bone of the maxillae or in bone graft sites in sinus maxillaries using the sinus lift technique with an osteotom. The number of healthy patients treated with implants in the study was 126 . The total number of implants was $232,1-6$ implants in each patient. Each patient was examined yearly with oral inspection and $\mathrm{x}$-ray. The follow-up period was 2 - 4 years (mean of 3 years). The results showed satisfactory implant survival rates of $99.6 \%$ after at least 2 years of clinical function. Only one implant was reported to have failed. However, in the radiological examinations, marginal bone loss of greater than $0.2 \mathrm{~mm}$ per year was observed in $22.8 \%$ of the cases. The study showed that maxillary sinus floor grafting could be performed where the maxillary bone does not offer adequate space for the implants without affecting the survival rate of these implants.

\subsection{Bone grafting}

Bone grafting is a frequently used method where autogenous bone is transplanted to defected jaws (Nyström et al 2004). The harvested bone can be placed as inlays or onlays both in the maxilla and in the mandible. Inlay means when the bone is placed inside, for example in the sinus maxillaries as a bone chip, particulate bone or in between two bony fragments. Onlay means when a bone block is fixed with titanium plates and screws on the buccal or lingual part of the alveolar ridge. However, bone grafting is time- consuming due to the extra time needed for the graft to augment until time for dental implant installation, typically 6 months. After the grafting procedure, the bone block becomes almost necrotic and will be incorporated by revascularization induced by the inflammatory reaction during the first week after implantation, the healing phase. In the case of cancellous particulate bone grafts, which have a larger surface area than the bone block, vascularization from the 
surrounding tissue occurs faster. It is incorporated quicker but there is also the risk of a faster resorption. Grafting will often necessitate general anesthesia and hospitalisation, which is costly to national healthcare systems. Despite the high success rate for the tilted implant procedure, today the gold standard is still autogenous bone grafts; not only for implant treatment but for all kinds of osseous defects in oral and maxillofacial regions. One side effect is that the bone cannot be expanded in the vertical height when using the onlay technique, only in the horizontal dimension which makes the alveolar crest wider so there is enough space for the implants. The inlay technique, however, can expand the alveolar bone in the vertical dimension in the maxilla. A Le Fort I osteotomy is used to expand the space for the transplanted autogenous bone and stabilization of the transplanted bone is made by titanium plates and screws (Fig. 2).
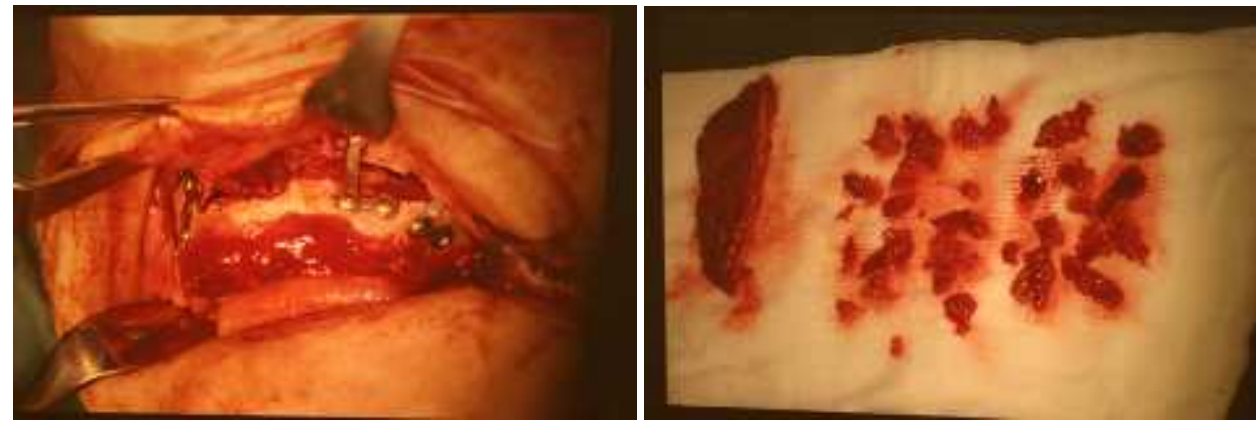

Fig. 2. Bone grafting, bone is taken from the iliac crest, and the Le Fort I technique is used to expand the vertical height in the maxilla.

This technique can be useful when the sagital dimension is not optimal for dental implant treatment. With the Le Fort I osteotomy the maxilla can be moved forward for optimal occlusion. Side effects, such as postoperative problems with the graft or host site morbidity can be observed as well as resorption of the bone if an extended healing time is required. It is very important to cover the osteotomy with a tension free flap otherwise, a gap in the incision area will be the result and the chances of an infection or the resorption of the transplanted bone increases. These surgical procedures also entail some risks in the form of nerve damage (Kahnberg, 2010).

\subsection{Synthetic bone building technique}

Bone-building therapies, such as synthetic bone, allogenic, or bone from different species, xenogenic, have been used extensively in the past with satisfactory results. However, the healing time for biomaterial grafts is longer than for autogenous bone and it may also give rise to rejection and infection. Rejection of the bone or possible transmission of infections from these types of bone-building therapies is a danger (Maiorana, 2010).

\subsection{Distraction osteogenesis}

Distraction osteogenesis (DO) is a method for either restoring atrophic jaws in the vertical dimension or for expanding congenital defected jaws in the orofacial region (Cheung et al 2010). DO is a clinical tissue engineering method with huge possibilities, even to treat severe 
deformities in the craniofacial area. Patients with hemi-facial asymmetries, extreme retrognatic maxillas or mandibles can be adjusted to normal positions. The device can be intra- or extraorally fixated with titanium screws in the bone. The major advantages are that bone grafts are not necessary and the technique allowing the soft tissue to expand in the oral region. The technique consists of five phases, the osteotomy, the latency, active distractor, consolidation and remodeling. The osteotomy triggers a biological process of bone repair. A blood clot appears and will be replaced by granulation tissue which consists of inflammation cells. Fibroblasts, collagen and invading capillaries fill the distracted bone space and stimulate the osteocytes. This technique can even be used in temporomandibular joint (TMJ) reconstruction, in cases with ankylosis where the condyle is resected. The TMJ distraction creates a neocondyle in the bone of ramus mandibulae, the bone moves gradually towards the glenoid fossa and the normal anatomical structures will be restored. Long term stability of the TMJ has been reported (Cheung et al 2007).

$\mathrm{DO}$ is a two-stage surgical technique and can be used when teeth are missing and the alveolar ridge needs to be vertically expanded with bone before dental implants are placed (Cano et al 2006) or in the cases of an open bite with good occlusion in the molar region of the jaws when conventional orthognathic surgery is not an alternative. A reliable patient is needed who must expand the device each day and it also necessitates a long retaining period including orthodontic treatment. After the retaining period the device has to be removed surgically. Infections, bone morbidity and distracter fractures are side effects that have been reported (Saulacic et al 2009).

Recently, two patient cases in our clinic with open bite and normal occlusion in the premolar and molar region were treated with the osteodistraction technique. Patient 1, a 22year old male with a three-year follow-up and patient 2, a 40-year old female with a twoyear follow-up were treated. The alveolar ridge was vertically expanded in the frontal maxillary area in both cases. The intra orally distraction devises were surgical inserted under general anesthesia (Fig. 3).

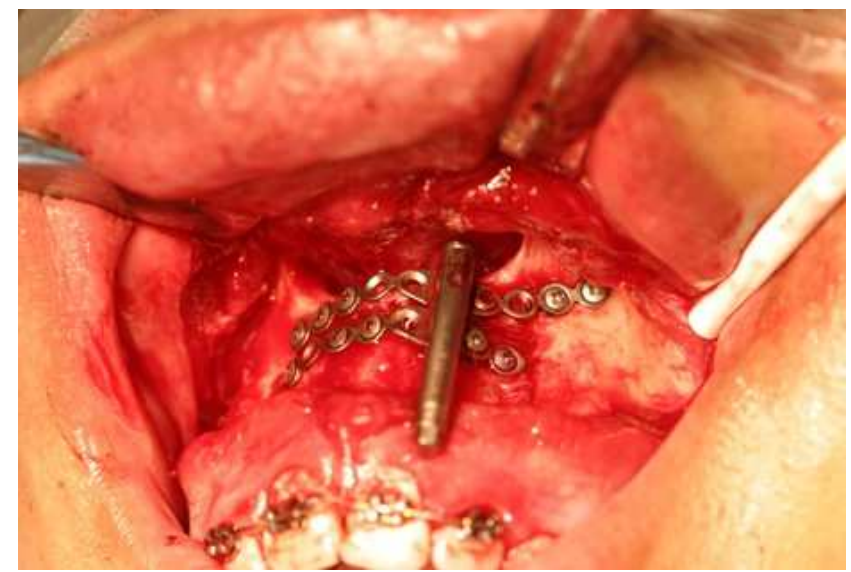

Fig. 3. The distraction device surgically inserted in the frontal maxilla in patient 1 .

After a couple of nights in hospital the patients went home and after approximately one week they were instructed to do the expansion two times a day. After three to four weeks 
the maxillary frontal regions were expanded to a normal occlusion. The orthodontic treatment started whilst the distraction device remained for a three month retaining phase. After a year, the orthodontic treatments were finished and good results were obtained in both patients. The patients were satisfied with the results and no side effects were seen (Fig. 4).

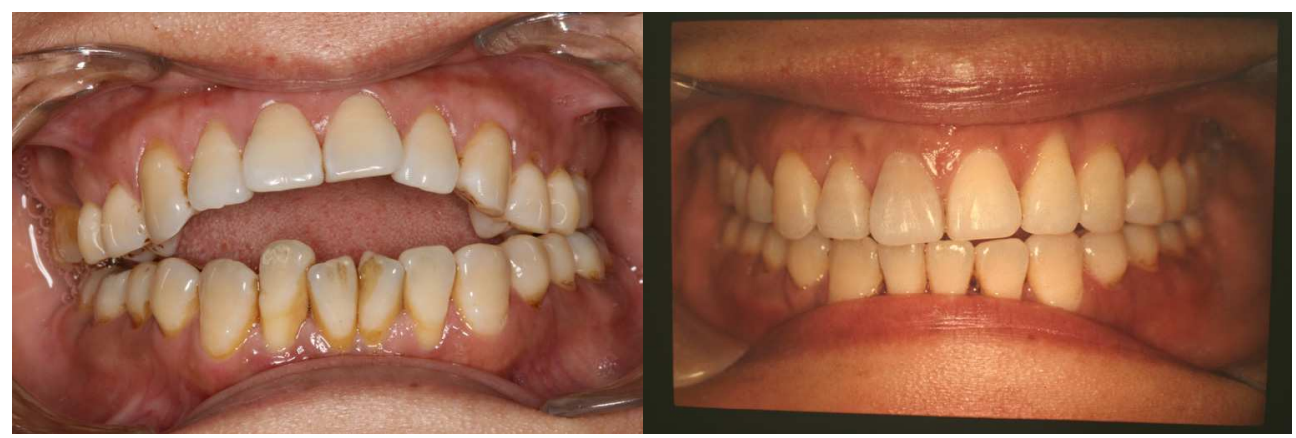

Fig. 4. Pre- and postoperative close up pictures of patient 2 with an open bite and treated with DO.

Patient 1 developed a necrotic tooth pulp after two years, which had to be endodontically treated, probably a side effect of the orthodontic treatment. A three year follow-up study will soon be reported (Rosén et al in manuscript).

\subsection{Surgically assisted rapid maxillary expansion (Sarme)}

Orthopedic maxillary expansion (OME) is a common method used in children for treating uni- or bilateral cross bites, cleft lip and palate, and patients with maxillary teeth crowding to gain arch length. In teenage children or in adults where the bone is mature and therefore harder, limited expansion occurs only with dental changes. Surgical procedures such as Le Fort I osteotomy for widening the maxilla in a transverse dimension has been an alternative to OME in teenage children and for adults. The combined surgical and orthodontic treatment for maxillary expansion with only tooth anchorage often show post retention relapses with the Hyrax-type expander. Several types of surgical assisted rapid maxillary expansion (SARME) devices with bone anchorage have thereafter been presented, the transversal palatinal Surgi-Tec, the Rotterdam Palatal distracter, the Magdeburg palatal distracter and the Smile distracter. Recently, a three year follow-up study was reported where OME or SARME were compared with a control group. The control group consisted of untreated, skeletal Class 1 subjects matched to the OME group in order to assess the effects of normal skeletal growth. The study showed that both the OME and the SARME procedures remained stable after three years with some amount of post retention relapses compared with the control group (Kurt et al 2010). In our clinic, we went one step further using a device with both tooth and bone anchorages (Fig. 6). A long time follow-up study of this technique will soon be presented. The study included 43 patients treated with the tooth and bone anchored device. Palatinal expansion up to $15 \mathrm{~mm}$ occurred, in patients where the canines had supra position and no space at all in the arch (Rosén et al, in manuscript). 


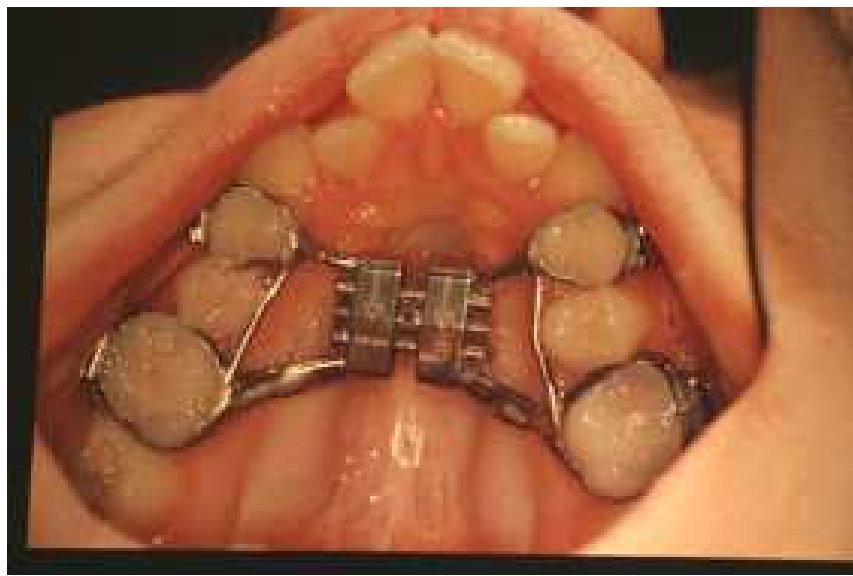

Fig. 6. A SARME device with both teeth and bone anchorages. Palatinal screws are hidden on each side under the posterior part of the device

\subsection{Osteogenesis imperfecta}

Osteogenesis imperfecta (OI) is an inherited genetic disorder. The connective tissues are affected throughout the whole body, including the dentin of the teeth. To date, seven types of OI have been identified varying from the mild Type I OI to the moderate Types IV and VI, severe Types III, V and VII to lethal Type II (Martin and Shapiro, 2007). Multiple fractures of long bones are frequently observed as well as disturbances of the permanent dentition. Orthognathic surgery in patients with OI is rare but necessary to correct the malocclusion for functional and esthetic reasons. Most cases result in a successful outcome with stable and good dental occlusion. Two patients probably with severe types I and IV OI, and malocclusion class III with retrognathic maxilla and prognathic mandible, were treated with orthodontic treatment and bimaxillary surgical correction (Rosén et al 2011).

Patient 1, a 26-year old male with most likely OI type IV was treated. Since childhood he had been treated for 18 fractures of the limbs and hips. The analysis indicated advancement of $8 \mathrm{~mm}$ of the maxilla and a setback mandible of $4 \mathrm{~mm}$. The surgical procedure was planned with certain precautions with a two step model. Firstly, a Le Fort I osteotomy where a stable occlusion was planned for so the surgery could be interrupted in case the bone was too brittle. Secondly, a setback vertical ramus osteotomy followed by an intermaxillary fixation for five weeks. We tested the bone in the maxilla with titanium screws before any osteotomies were performed to ensure their function in the soft bone before continuation. We planned to use wires or a halo frame for stabilization if the bone proved to be too soft. The surgical outcome in patient 1 was good and the surgery was made in one session. The maxillary bone was thin and teeth were brittle but the orthodontic anchorage was stable enough to fixate the jaws together and the titanium screws remained stable in the bone when the titanium plates were fixed over the osteotomies.

Case 2, a 22-year old male with OI severe type I was planned for a $10 \mathrm{~mm}$ advancement of the maxilla with a Le Fort I osteotomy and 6-7 $\mathrm{mm}$ set back with a vertical ramus osteotomy of the mandible. A bone graft from the iliac crest was planned if necessary. However, there 
was no need for bone graft during surgery and the operation followed a routine fashion and was completed after five weeks of intermaxillary fixation. We concluded that it was possible to perform combined orthodontic and orthognathic surgery in patients with OI despite the greater risk of complications such as fractures in the soft bone and loss of orthodontic anchorage in brittle teeth. The treatments were successful in both cases with follow-up times of five to six years (Fig. 7, Rosén et al 2011).

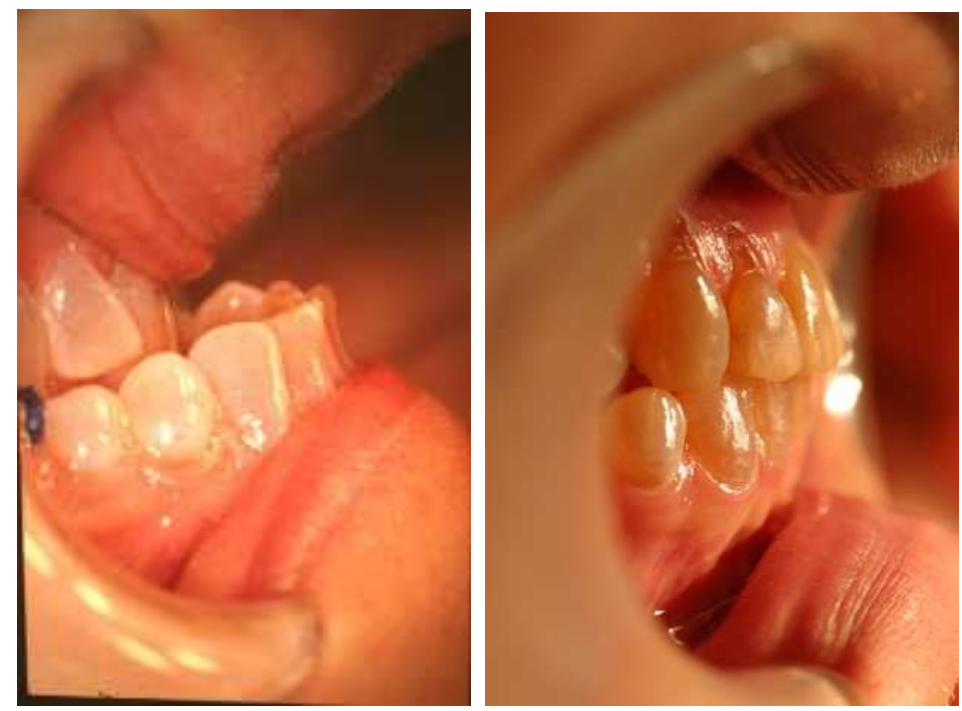

Fig. $7 \mathrm{a}$ and b. Surgically treated patient with OI. The patient no. 1 underwent bimaxillary surgery and the profile photos are pre-and postoperative.

\section{Biological considerations}

The dynamic interplay between the cells and the environment is essential to ensure successful bone formation and regeneration, a feature easily forgotten during the establishment of new clinical strategies. Therefore to fully understand bone grafting and regeneration an appreciation of bone mineralization, and the interplay with the biochemical environment is necessary. In many cases after maxillofacial surgery, wound healing occurs before new bone is deposited. Bone formation is a carefully balanced process involving the secretion of an organic pre-mineralized matrix, osteoid, that becomes mineralized with inorganic hydroxyapaptite (HAP) crystals and its subsequent resorption and remodeling. The interactions with the surrounding biochemical milieu stimulate cell migration, adhesion, proliferation, differentiation, transcription and translation. Resulting in the synthesis and secretion of an extracellular matrix (ECM) that acts as a scaffold for mineral deposition and nucleation, and serves to sequester and protect growth factors.

\subsection{Wound healing}

Wound healing is a unique and complex system, where the healing of both soft and hard tissues needs to be fully integrated. For this to occur a coordinated series of events must be 
induced, i) stimulation of an initial inflammatory response, ii) the recruitment of specific cell types and iii) induction of their proliferation leading to bone formation. A model has been devised for wound healing in the epithelia but it is also relevant in this context, particularly with DO (Wikesjsö et al, 2010). Initially, clots form followed by early stages of inflammation with the infiltration of inflammatory cells, such as neutorphils and monocytes into the clot. This takes place just hours after damage and cleanses the wound of bacteria and necrotic debris. After a few days, the late phase of inflammation is initiated along with macrophages infiltrating into the wound. Macrophages assist the formation of granulation tissue and the release of growth factors that stimulate fibroblasts. The granulation tissue matures becoming rich in cells and the collagen-rich ECM provides a suitable environment for further cell propagation and reconstruction of the vasculature prior to bone formation.

\subsection{Bone formation}

Bone formation occurs by two distinct condensation processes; endochondral, which forms the long bones and intramembraneous that results in the flat bones of the jaws and calvaria. Endochondral bone formation occurs when mesenchymal stem cells (MSCs) migrate and condensate at a high density at regions where skeletal rudiments will develop. MSCs differentiate into chondrocytes to form an avascular anlagen, into which they secrete an ECM rich in type II collagen and aggrecan, and express typical chondrocytic transcription factors, such as Sox 5/6/9. As proliferation ceases, the epiphyseal growth plate begins to form with the cells becoming hypertrophic, synthesizing type $X$ collagen and blood vessels finally penetrate into the cartilage template. The hypertrophic chondrocytes undergo apoptosis and are replaced by osteoblasts recruited from the perichondrium to form the bone collar and together with bone elongation create the bone marrow space. In comparison, intramembraneous ossification results from the direct condensation and differentiation of MSCs into osteoblasts in regions that are rich in blood vessels. The resulting woven or primary bone forms rapidly, particularly during embryogenesis, in the case of DO, after fracture healing and during adaptive bone gain after mechanical loading. Despite these two distinct formation pathways both types of bone share some common molecular and cellular control mechanisms.

\subsection{Bone cell differentiation}

Biomineralization is a dynamic process driven by active osteoblasts that initially secrete an osteoid that eventually becomes mineralized. The mature cells are polarized and cuboidal, a proportion of which are termed bone-lining cells and become flattened and align along the bone surface. Whereas the remainder become entrapped and embedded within the forming mineralized tissue within the lacunae of the matrix called osteocytes. The precise function of osteocytes remains to be clarified however evidence suggests that the cells have a role in response to mechanical stimuli, as a mechanoreceptor (Aarden et al, 1994).

Osteoblast progenitors are derived from MSCs, which originate as pericytes along the blood vessels within the bone marrow in a niche that is finely balanced with hematopoiesis (Bianco et al, 2011). MSC differentiation gives rise to a number of different lineages that acquire specific phenotypes under the control of specific regulatory factors. Characterization of the osteoblast differentiation process has been defined into three stages; a growth or 
proliferation stage, matrix maturation stage and mineralization stage. During the first phase of growth and proliferation the cells exhibit high mitotic activity and actively express cellcycle associated genes. At this time ECM associated molecules are synthesized including collagen type I, osteopontin (OPN) and fibronectin. Collagen type I continues to be expressed with proliferation but at low levels whereas the other ECM proteins are all downregulated. As the cells move into the second stage of matrix maturation, alkaline phosphate levels dramatically increase and there is considerable secretion and organization of the organic ECM in preparation for the final phase of mineralization and the deposition of HAP crystals. The secreted ECM molecules play a considerable role in this dynamic process, including collagen type I, glycoproteins, sialoproteins and proteoglycans, and their roles will be discussed in more detail below.

Each of the phases of osteoblast differentiation is characterized by a set of specific genes and regulatory molecules that allow progression into the next stage (Marie, 2008). The initial and key transcription factor is Runx2, also known as Core-binding factor alpha 1, a member of the Runt-related factors (Runx) family of transcription factors. Runx2 activates vital bone ECM genes, including collagen type 1 alpha 1 (COL1A1) and osteocalcin (OCN). It is important to note that Runx2 is also expressed by cells other than osteoblasts, including chondrocytes, T-cells and other mesenchymal cells. However, two separate promoters have been identified; an upstream promoter that specifically drives the expression of osteoblastspecific isoforms, whereas the downstream promoter activates Runx2 isoforms in T-cells, although some expression has been identified in osteoblasts (Harada et al, 1999). Runx2 is essential for both endochondral and intramembraneous bone formation, as targeted disruption of the gene results in a complete lack of bone formation in both processes (Komori et al, 1997). On the other hand, over expression of Runx2, such as by skin fibroblasts, which do not normally express the molecule, exhibit osteoblast-specific gene expression (Takeda et al, 2001). In addition to being the initiator of osteoblast differentiation, it functions as an inhibitor of progenitor proliferation and is required for terminally differentiated osteoblast function. Downstream of Runx2, osterix (OSX, Sp7), a zinc-fingercontaining transcription factor and bone morphogenic protein (BMP) 2-inducible gene has been identified as the regulator of the final stages of bone formation (Nakashima et al, 2002). In similarity to Runx2, OSX also activates COL1A1 and OCN, and in a transgenic null mouse model no endochondral or intramembraneous bone formation was detected. Upstream of Runx2 the picture is less clear. A few transcription factors have been identified; Twist-1 is down-regulated for Runx2 activation, Msx2 and Bapx1 both regulate the expression of Runx2 (Huang et al, 2007). Additional studies have demonstrated the importance of signaling pathways that may act in parallel or independently of Runx2 to regulate osteoblast differentiation.

Osteoblasts also influence the differentiation of bone resorbing cells, osteoclasts. Osteoclasts derive from the monocytic / macrophage lineage and are multi-nucleated cells. The main regulatory pathway involved during osteoclast differentiation is through the receptor for activation of nuclear factor kappa B ligand (RANKL) / RANK / osteoprotegerin (OPG) pathway. Osteoblasts express RANKL and macrophage-colony stimulating factor (M-CSF), which activate a number of signaling pathways in osteoclasts. However, OPG acts as a decoy receptor for RANKL inhibiting the RANK / RANKL interaction, and in turn osteoclast differentiation. Local and systemic factors, such as parathyroid hormone (PTH) also 
promote osteoclast differentiation by increasing RANKL expression by osteoblasts. RANKL has also been implicated in the regulation of mature osteoclasts. OPG over-expressing transgenic mice exhibit severe osteopetrosis, impaired tooth eruption due to the lack of osteoclasts (Kong et al, 1999).

\subsection{Extracellular matrix: collagenous and non-collagenous components}

The organic matrix of bone is comprised of $90 \%$ collagen type I and additional noncollagenous components (Table 1), some of which have important functions in bone formation. Furthermore, the ECM is a vial source of factors that play crucial roles in cell signaling and the modulation of mineralization, such as BMPs. Most of these proteins and factors are produced locally by osteoblasts but others, like the serum proteins are synthesized elsewhere and delivered to the developing bone via the circulation.

\begin{tabular}{ccc}
\hline \multicolumn{4}{c}{ Extracellular Matrix } & \\
\hline Collagenous & Non-Collagenous & Enzymes \\
\hline \multirow{2}{*}{ Type I } & $\gamma$-carboxyglutamic acid containing & TNAP \\
& $-\quad$ OCN, MGP, Periostin & MMPs \\
\multirow{2}{*}{ Type X } & Glycoproteins & $1,2,8$ and 9 \\
\hline \multirow{2}{*}{ Type III } & ON, FN, COMP & TIMPS \\
& Sialoproteins & 1,2 and 3 \\
\hline \multirow{2}{*}{ Type V } & BSP, OPN & \\
& GAG - containing leucine rich repeat proteins & \\
& Aggrecan, Versican, DCN, BGN, FMD, LM, & \\
& OSAD & \\
\hline
\end{tabular}

$O C N$-osteocalcin, $M G P$ - matrix gla protein, TNAP - tissue non-specific alkaline phosphatase, $O N$ - osteonectin, DMP1 - dentin matrix protein 1, FN - fibronectin, COMP - thrombospondin, $M M P$ - matrix metalloproteinase. BSP - bone sialoprotein, OPN - osteopontin, TIMP - tissue inhibitor of MMPs, GAG - glycosaminoglycan, DCN - decorin, BGN - biglycan, FMD - fibromodulin, $L M$ lumican, $O S A D$ - osteoadherin

Table 1. Principal ECM-associated molecules implicated in the biomineralization process

Collagens are responsible for maintaining the structure and function of bone. In particular, fibrillar collagens, principally type I, are important in biomineralization, whereby they facilitate the formation of an ECM scaffold in which crystal nucleation occurs and subsequent crystal elongation spreads through the organized matrix. Disorders that disrupt collagen synthesis have significant effects on bone formation. In the case of OI, mutations have been identified affecting collagen type I genes, COL1A1 and COL1A2. Collagens play a crucial role during boney healing by aiding the formation of early bone spinicles that extend from the damaged / surgical site toward the center of the defect. The spinicles form the primary mineralization front associated with successful union of the surrounding bones. New bone formation associated with DO forms through the deposition of primary bone via intramembranous ossification. In a rat model of DO, studies have demonstrated that collagen type I is up-regulated ten days after osteotomy, which continues with mineralization (Fang et al, 2004). 
The remaining non-collagenous proteins of bone have been implicated in the modulation and regulation of biomineralization. Most are highly anionic and have a strong ion-binding capacity. The $\gamma$-carboxyglutamic acid containing protein, $\mathrm{OCN}$ is known to be one of the few molecules that are truly mineralized tissue-specific (Bronckers et al, 1985). OCN acts as a regulator of mineralization through the inhibition of spontaneous mineral deposition and HAP crystal growth (Romberget al, 1986). In DO rat models, OCN levels have been shown to correlate with successful treatment, gradually increasing from mid-activation and consolidation (Allori et al, 2008b; Fang et al, 2004). Osteonectin (ON), accounts for $15 \%$ of all non-collagenous proteins. It is proposed that $\mathrm{ON}$ has a role as a nucleator in collagenmediated mineralization but also it may have a role in the inhibition of cell proliferation, modulates cell-matrix interactions, and binds and regulates HAP crystal growth (Brekken et al, 2001). A significant family of non-collagenous proteins is the small integrin-binding ligand N-linked glycoproteins (SIBLINGs). All clustered on human chromosome 4, they include bone sialoprotein (BSP) and OPN. BSP is osteoconductive, osteoinductive, promotes cell attachment, stimulates osteoblast proliferation and differentiation and importantly serves as a nucleator of mineralization (Gordon et al, 2007; Tye et al, 2003). The proteoglycan family consists of more than 30 proteins that are post-translationally modified with glycosylation or the addition of a glycosaminoglycan (GAG) chain. Small leucine-rich proteoglycans (SLRPs) have a core protein and contain one or more GAG chains including chondroitin or dermatan sulphate, heparin or keratin sulphate. Studies have shown SRLPs, in particular chondroitin sulphate-containing decorin and biglycan to bind collagen and to regulate HAP crystal growth (Sugars et al, 2003). In addition, osteoadherin (OSAD) is currently believed to be mineralized tissue-specific, with a role in inhibiting actively proliferating cells, to binding collagen and HAP (Wendel et al, 1998). Furthermore, OSAD has been found to have a similar distribution pattern as BSP in rat long bones and calvaria (Ramstad et al, 2003).

The final group of molecules that requires consideration in the ECM are enzymes, specifically tissue non-specific alkaline phosphatase (TNAP) and matrix metalloproteinases (MMPs). The current belief is that matrix mineralization is initiated through the expression of TNAP by osteoblasts. It functions to increase the relative concentration of phosphate by inactivating pyrophosphate, so that HAP becomes the main product. In disease states, such as rickets and osteomalacia, TNAP is either inactive or expressed at low levels resulting in a reduced amount of mineralization (Fedde et al, 1999). An important feature of bone formation and repair is the ability to remodel to create an environment and scaffold in which mineralization can occur. MMPs and their inhibitors, tissue inhibitors of MMPs (TIMPs) fulfill this goal and are designed to specifically degrade particular ECM components. For example, collagenases (MMP1) have been involved in fracture healing and $\mathrm{DO}$, and gelatinases (MMPs 2, and 9) in osteoclastic remodeling. In addition, matrix degradation allows for growth factors and /or signaling molecules sequestered in the ECM to be released to act on early by cells (Weiss et al, 2002). MMPs also act to facilitate cell migration, influence osteogenesis and vascularization.

\subsection{Growth factors and signaling molecules}

The regulation of osteoblast differentiation, bone formation and turnover involves signaling molecules such as growth factors, hormones and cytokines (Table 2). These maybe secreted 
endogenously by local cells or absorbed from the blood. Growth factors are synthesized as biologically inactive propeptide forms and stored in the cytoplasm or ECM. They initiate their effect by binding to cell surface receptors and following intricate intracellular signaling transduction pathways to transmit signals to the nucleus, resulting in the activation of specific target genes that regulate cellular activity and or phenotype. Many act locally or systemically and affect target genes in a variety of ways; autocrine, intracrine, paracrine, juxacrine, and finally endocrine. All these mechanisms are highly regulated through a complex system of feedback loops and interactions involving other growth factors, hormones and binding proteins, as well as regulatory factors that act on extra and intracellular levels.

Principal growth factors implicated in bone formation and turnover include the transforming growth factor - $\beta$ (TGF- $\beta$ ) family, BMPs, insulin-like growth factor (IGF), epidermal growth factor (EGF), fibroblast growth factor - 2 (FGF2), platelet-derived growth factor (PDGF) and vascular endothelial growth factor (VEGF). TGF- $\beta$ isoforms 1,2 and 3 are capable of exerting the same functional activity but with slight structural differences, for example TGF- $\beta 1$ has been observed at sites of osteogeneis but TGF- $\beta$ 's 2 and 3 at sites of chondrogenesis (Schmid et al, 1991). TGF- $\beta$ 's can stimulate osteoblast migration, and is a potent regulator of cell proliferation, cell differentiation and ECM maturation (Janssens et al, 2005). However, TGF- $\beta$ 's are unable to initiate the osteoblast and bone formation cascade at extraskeletal sites, unlike BMPs. Both TGF- $\beta$ 's and BMPs act via BMP receptors types I and II, and Smad 1 / 5 / 8 molecules. Phosphorylation of the Smads following binding of the BMP to the receptor causes translocation into the nucleus in a complex with Smad4, where they regulate target genes. BMPs 2, 4 and 7 are collectively known as the osteogenic BMPs as they have been shown to induce ectopic bone formation (Bragdon et al, 2011). Regulation of osteoblast differentiation results from the interaction of the complex of Smad $1 / 5$ / and 8 with Smad 4 on target genes, specifically Runx2 and OSX.

\begin{tabular}{ccc}
\hline & Signaling Molecules & \\
\hline Growth factors & Hormones & Cytokines \\
\hline TGF- $\beta$ & PTH & Interferon $\gamma$ \\
BMP & Calcitonin & Interleukins 1 and 6 \\
FGF & Estrogen & Prostaglandins $\mathrm{E}_{2}$ and $\mathrm{I}_{2}$ \\
Activin A & Thyroxine & \\
PDGF & & \\
IGF-1 & & \\
VEGF & & \\
\hline
\end{tabular}

$T G F$ - transforming growth factor, $P T H$ - parathyroid hormone, BMP- bone morphogenic protein, $F G F$ - fibroblast growth factor, CSF -colony stimulating factor, PDGF - platelet derived growth factor, IGF insulin growth factor, VEGF -vascular endothelial growth factor

Table 2. Signaling molecules involved in the regulation of bone formation and bone remodeling

A number of hormones contribute to the regulation of bone formation and turnover. Specifically of interest are PTH and calcitonin that facilitate osteoblast differentiation and 
calcium storage respectively (Allori et al, 2008a). PTH is secreted in response to decreased levels of calcium. Calcium release into the bloodstream following bone destruction by osteoclasts stimulates PTH and its downstream effector vitamin D3. PTH stimulates RANKL and M-CSF expression in osteoblasts but conversely inhibits OPG synthesis that in turn prevents RANKL binding to RANK. The actions of PTH and BMPs are closely linked with the activation of the Wnt signaling pathway. The Wnt / $\beta$-catenin (canonical) pathway governs osteoblast differentiation and is initiated through the formation a receptor complex, composed of Frizzled receptors and low density lipoprotein receptor-related proteins 5 and 6, on the cell surface (Westendorf et al, 2004). Activation of the canonical Wnt pathway promotes osteoblast differentiation from MSCs at the expense of adipocytes, leading to improved bone strength (Bodine et al, 2006).

\subsection{Mineral composition and mechanisms of biomineralization}

The major mineral component of all calcified tissues is biological apatite, a calcium phosphate that is very closely related to the geologic mineral HAP $\left(\mathrm{Ca}_{10}(\mathrm{OH})_{2}\left(\mathrm{PO}_{4}\right)_{6}\right)$. In comparison to naturally occurring apatite, the mineral of bone differs in a number of respects, firstly biological HAP readily incorporates impurities such as $\mathrm{CO}_{3}{ }^{2-}, \mathrm{F}-$, and $\mathrm{Na}^{+}$ into the crystal structure that are absent in pure HAP, second the theoretical calcium/phosphate ratio of pure HAP is 1.667 but this can vary from 1.5 to 1.7 , leading to the term "calcium-deficient", finally a small percentage of water is present in biological HAP, making its crystallinity less than perfect. The skeleton contains $99 \%$ of the body's calcium, $35 \% \mathrm{Na}^{+}, 60 \% \mathrm{CO}_{3}{ }^{2-}$ and $60 \% \mathrm{Mg}$ (Boivin et al, 2003).

Biomineralization results from two stages; mineral nucleation to form HAP crystals, and subsequent HAP crystal growth, both involving the presence of the three-dimensional ECM framework. The process by which nucleation is initiated is a constant source of debate and include biomineralization foci, calcospherulites and matrix vesicles. Matrix vesicles have long been contested as sites of nucleation in bone and recent data suggested that the vesicles are present in bone but that they vary in size and the composition (Gorski, 2011). Vesicles have also been shown to be present within biomineralization foci (Huffman et al, 2007). Biomineralization foci (10-25 micron diameter) are the result of ECM-mediated nucleation. These foci are rich in acidic phosphoproteins, such as BSP and bone acidic glycoprotein - 75 , as well as immature collagen type I. Biomineralization foci have been detected in the periosteum of developing bones and in primary bone (Gorski et al, 2004).

\subsection{Bone remodeling}

Bone remodeling is a highly controlled and balanced process, ensuring the successful replacement of old bone with new through the sequential resorption by osteoclasts and subsequent bone formation by osteoblasts. Through this process bone remodeling ensures skeletal integrity throughout life. Currently, bone remodeling is considered to occur via either targeted or non-targeted remodeling (Eriksen, 2010). Non-targeted remodeling is proposed to be modulated by the osteoclasts themselves via hormones such as PTH, thyroxine and estrogen and some anti-resportive drugs like bisphosphonate. Whereas, targeted remodeling, specifically removes damaged bone and the injury of osteocytes may be the event that stimulates osteoclastic resporption. In fact, damaged osteocytes secrete MCSF and RANKL that promote osteoclast differentiation (Kurata et al, 2006). Bone resorption 
occurs with the formation of the ruffled border composed of finger-shaped projections of the osteoclast membrane that mediates the process. The ruffled border forms on the surface of the bone and is only present when active resorption is occurring. This structure is also surrounded by a "clear zone", to form a microenvironment that defines the area destined to be resorbed. The mineral is dissolved through the action of an ATP-driven proton pump located in the membrane of the ruffled border. ECM, such as collagen and non-collagenous proteins are degraded through the action of MMPs, tartrate resistance acid phosphatase (TRAP) and cathespins K, B and L that are secreted by the osteoclast into the resorptive area (Bossard et al, 1996). Degraded protein components are endocytosed along the ruffled border within resorption lacunae, which are then transported to the membrane on the opposite side for release (Nesbitt et al, 1997).

\section{Tissue engineering approaches and future perspectives}

As highlighted above autogenous bone grafting is the most common surgical approach to treat bone defects however it does have its drawbacks including failure and rejection. There are three fundamental requirements for tissue regeneration to ensure the formation of good quality tissues that can withstand the demands of normal function: i) a source of cells to drive the regenerative process; ii) a source of growth factors and nutrients; and iii) a suitable biomaterial which can support and sustain the growth of the new tissue. However, obtaining these three components remains a challenge to tissue engineers.

\subsection{Biomaterials}

Several important properties, biological and physical, must be considered when developing and choosing the "ideal" biomaterial for bone grafting and regeneration procedures. The material should provide stability and possess the ability to promote osteogenesis. Physical properties include the ability to be sterilized, slow degradation rate, a high initial stiffness, a load-bearing capacity; it should be easily processed into complex-shapes and storable. Biologically, the material should be bioresorbable, biocompatible, capable of revascularization, with a highly porous and interconnected pore network to facilitate the flow and transport of nutrients and metabolic waste. In addition, the biomaterial should be either osteoconductive or osteoinductive. Osteoconductive materials act as a scaffold and the grafted material does not contribute to new bone formation per se. As a result an osteoconductive material enhances native bone formation in an orthotopic site. Whereas, with an osteoinductive material, it can induce bone formation in an ectopic site, in the surrounding soft tissue immediately adjacent to the grafted material by release of growth factors or other stimulatory mediators.

Four types of bone graft or substitute materials are available, autogeneous, allogenic, xenogeneic grafts and alloplastic materials. Autogeneous grafts have already been discussed, however it should be highlighted that this type of bone graft are the most osteoinductive and there is little immunological rejection. In addition, a surgical donor site is required and these tend to have a high morbidly rate. Alternatively, allogeneic grafts are widely used and occur between genetically dissimilar members of the same species. Typically frozen cancellous or freeze-dried demineralized bone is used. These grafts are both osteoconductive and osteoinductive but there is the possibility of disease transmission, loss of bone and osteogenic potential due to the treatments, and a high chance of an 
immunological response. Xenogeneic grafts are widely used, whereby the material is taken from the donor of another species, for example bovine. These materials are osteoconductive and do show some potential for osteoinduction but again there is the potential for disease transmission. The final type of bone graft materials are the bone fillers, synthetic or inorganic alloplastic materials that are used as bone substitutes, including HAP, $\beta$-tricalcium phosphate, polymers and bioactive glass. It remains a challenge for the bioengineers to develop a suitable biomaterial to stimulate regeneration. Modifications to provide a biomimetic surface are a particular area of study. To facilitate cell attachment is one example, and many modifications exploit cell binding motifs, such as the RGD-sequence.

\subsection{Cells}

In addition to the bone-building materials outlined above, the cell source has been a considerable focus in regenerative strategies. Obtaining sufficient numbers of cells with the appropriate phenotype has been a considerable challenge to the field of regenerative medicine. Ideally endogenous cells from the surrounding milieu would migrate into the defect area in the presence of a scaffold or support by cell homing. Indeed, osteoblasts may migrate from an autologous bone graft to stimulate bone formation. However, allograft, xenograft or synthetic materials lack this cell population and may require the additional application of cells. To produce bone from human stem cells could be a way to minimize the morbidity side effects. Adult stem cells have been at the forefront of regenerative medicine, in particular bone marrow-derived MSCs. However, limitations exist to using these cells as they are difficult to obtain in sufficient number due to technical problems and they are "tissue or organ-specific". Pluripotent stem cells have revolutionized stem cell research and will in all likelihood have an immense impact on the treatment of various diseases in the future. At present, groups are studying the cell lines characteristics, and developing directed differentiation strategies to the required cell type. Pluripotent stem cells, human embryonic stem cells (HSEC) or induced pluripotent stem cells (iPSCs) could overcome the obstacles hampering adult stem cell therapies. This is particularly true since derivation and culture methods have advanced considerably, and cell lines now exist that are xeno-free and could potentially be used for therapeutic purposes if the correct differentiation pathways were established.

A considerable number of studies have been performed on HESCs to induce osteogenic differentiation with many different approaches being taken (reviewed by Brown et al, 2011). Many groups have performed direct osteogenic differentiation, whereas others have taken the cells through a MSC progenitor stage prior to osteoblasts (Arpornmaeklong et al, 2009; Brown et al, 2009; Karp et al, 2006). Our own studies have shown that HESC lines differentiate along the osteogenic lineage, forming a fully mineralized bone-like matrix (Kärner et al, 2009; Kärner et al, 2007). We demonstrated the osteoblast phenotype using a large panel of extracellular matrix molecules and transcription factors (Kärner et al, 2007), and showed the dynamic gene expression of these markers (Kärner et al, 2009). In addition we characterized the deposited mineral with Fourier InfraRed spectroscopy proving that it resembled natural bone and was formed by cell-mediated mineralization. From these studies, we established a model system by which to define pluripotent stem cell osteogenic differentiation. Many technical difficulties remain be to overcome using HESCs therapeutically, as patient-matched or disease-specific HESCs will be difficult to generate, in addition to the many ethical issues to consider. One major break-through and potential 
solution to the problems associated with HESCs has been the derivation of iPSCs, which could eventually lead to patient-matched tissue regeneration treatments such as bone. Whether iPSCs behave in a similar manner as HESCs in terms of osteogenic differentiation remains to be determined, however the osteogenic capacity of mouse iPSCs to regenerate bone has recently been established (Bilousova et al, 2011).

Recent studies have shown that transplantation of bone grafts from a site of mesoderm tissue, such as the case of bone grafting onlay techniques, taking bone from the iliac crest to the mandible, which is neural crest derived contributes to the failure of the graft to fully integrate and regenerate bone to the standard required to withstand compressive functional processes (Chan et al, 2009; Leucht et al, 2008). These studies showed that the cell populations were not interchangeable, in that mesoderm-derived cells grafted into tibia defects produced osteoblasts but when transplanted into the mandible formed chondrocytes, and the reverse was true for neural crest-derived cells. The authors also reported that this regeneration was attributable to the homeobox gene expression pattern during embryonic development and referred to this phenomenon referred to as "positional memory" (Leucht et al, 2008). Such a finding is of considerable importance to the field of regenerative medicine, and techniques used for bone grafting procedures.

\subsection{Growth factors}

The ability to retain and release growth factors into the surrounding environment is crucial to ensure that cells home to the site of tissue repair and to stimulate regeneration. This has been a limiting factor to the field of tissue engineering and many obstacles remain to be overcome, including, identification of the ideal carrier, how can we sequester the growth factors to the carrier so that they remain biologically active and what is the correct dosage of the factor? Many of the growth factors are recombinantly produced, such as the BMPs and at present the amounts used for regeneration are significantly larger than those endogenously present. Adding to this is the huge cost of producing such large amounts of recombinant protein in a highly purified form.

Growth factors that are commonly used for bone regeneration include BMPs, TGF- $\beta$, FGF, VEGF, IGF, PDGF, EGF, PTH / PTH (related protein) (PTHrP) and interleukins. BMPs are involved in many developmental processes but these factors have been most widely studied in terms of bone engineering and bone replacement. Osteoblasts synthesize BMPs and sequester them in the ECM. BMPs are osteoinductive molecules and when placed ectopically they can initiate the whole pathway of bone formation from MSC differentiation to the entrapment of terminally differentiated osteoblasts as osteocytes (Wozney et al, 1988). Typically they are used in combination with many of the other factors or in combination with other family members. BMP2 and 7 have been successfully used together to facilitate boney healing (Koh et al, 2008;Ripamonti et al, 1997). The use of TGF- $\beta$ 's for bone regeneration has been extensively evaluated and show both stimulatory and inhibitory effects on bone formation. Despite differences in experimental setups, combined TGF- $\beta$ / BMP studies show additive or synergistic effects on bone formation (Si et al, 1998; Sumner et al, 2006).

Although in many studies it has been shown that just one of these factors has been adequate to stimulate molecular and cellular events leading to regeneration, however during the 
natural healing process many growth factors and signaling molecules are involved simultaneously or through a cascade of events and to date it has not been possible to recapitulate this. A combination of several factors is likely to be more effective to assist boney healing.

\section{Conclusions}

This paper brings together clinical concepts and novel findings to the field of bone regeneration and highlights some considerations necessary when devising new strategies to treat oral-facial hard tissue defects. It is apparent from the studies described above that individuals respond differentially to stimulus; therefore future tissue engineering approaches with biomaterials, cells or growth factors will need to be tailored to the patient.

\section{References}

Aarden, E. M.; Burger, E. H.; Nijweide, P. J. 1994 Function of osteocytes in bone, J Cell Biochem, 55, 287-990730-2312.

Allori, A. C.; Sailon, A. M.; Warren, S. M. 2008b Biological basis of bone formation, remodeling, and repair-part I: biochemical signaling molecules, Tissue Eng Part B Rev, 14, 259-731937-3376.

Allori, A. C.; Sailon, A. M.; Warren, S. M. 2008a Biological basis of bone formation, remodeling, and repair-part II: extracellular matrix, Tissue Eng Part B Rev, 14, 275831937-3376.

Arpornmaeklong, P.; Brown, S. E.; Wang, Z.; Krebsbach, P. H. 2009 Phenotypic characterization, osteoblastic differentiation, and bone regeneration capacity of human embryonic stem cell-derived mesenchymal stem cells, Stem Cells Dev, 18, 955-681557-8534.

Bianco, P.; Sacchetti, B.; Riminucci, M. 2011 Osteoprogenitors and the hematopoietic microenvironment, Best Pract Res Clin Haematol, 24, 37-471532-1924.

Bilousova, G.; Jun du, H.; King, K. B.; De Langhe, S.; Chick, W. S.; Torchia, E. C.; Chow, K. S.; Klemm, D. J.; Roop, D. R.; Majka, S. M. 2011 Osteoblasts Derived from Induced Pluripotent Stem Cells form Calcified Structures in Scaffolds Both In Vitro and In Vivo, Stem Cells, 29, 206-161549-4918.

Bodine, P. V.; Komm, B. S. 2006 Wnt signaling and osteoblastogenesis, Rev Endocr Metab Disord, 7, 33-91389-9155.

Boivin, G.; Meunier, P. J. 2003 The mineralization of bone tissue: a forgotten dimension in osteoporosis research, Osteoporos Int, 14 Suppl 3, S19-240937-941X.

Boyne, P. J. 1969 restoration of osseous defects in maxillofacial casualities, J Am Dent Assoc, 78, 767-76.

Bossard, M. J.; Tomaszek, T. A.; Thompson, S. K.; Amegadzie, B. Y.; Hanning, C. R.; Jones, C.; Kurdyla, J. T.; McNulty, D. E.; Drake, F. H.; Gowen, M.; Levy, M. A. 1996 Proteolytic activity of human osteoclast cathepsin K. Expression, purification, activation, and substrate identification, J Biol Chem, 271, 12517-240021-9258.

Bosshardt, D. D.; Sculean, A. 2009 Does periodontal tissue regeneration really work?, Periodontol 2000, 51, 208-191600-0757.

Bragdon, B.; Moseychuk, O.; Saldanha, S.; King, D.; Julian, J.; Nohe, A. 2011 Bone morphogenetic proteins: a critical review, Cell Signal, 23, 609-201873-3913. 
Brekken, R. A.; Sage, E. H. 2001 SPARC, a matricellular protein: at the crossroads of cellmatrix communication, Matrix Biol, 19, 816-270945-053X.

Bronckers, A. L.; Gay, S.; Dimuzio, M. T.; Butler, W. T. 1985 Immunolocalization of gammacarboxyglutamic acid containing proteins in developing rat bones, Coll Relat Res, 5, 273-810174-173X.

Brown, S. E.; Krebsbach, P. H. 2011I. Derivation of mesenchymal stem cells from human embryonic stem cellsI, In: Embryonic Stem Cells: The Hormonal Regulation of Pluripotency and EmbryogenesisI, Atwood, C.I, pp 649-670I, InTechI, Retrieved from: http://www.intechopen.com/articles/show/title/derivation-of-mesenchymalstem-cells-from-human-embryonic-stem-cells

Brown, S. E.; Tong, W.; Krebsbach, P. H. 2009 The derivation of mesenchymal stem cells from human embryonic stem cells, Cells Tissues Organs, 189, 256-601422-6421 .

Brånemark P. I.; Adell R.; Albrektsson T.; Lekholm U.; Lindström J.; Rockler B. 1984 An experimental and clinical study of osseointegrated implants penetrating the nasal cavity and maxillary sinus. J Oral Maxillofac Surg, 42(8):497-505.

Chan, C. K.; Chen, C. C.; Luppen, C. A.; Kim, J. B.; DeBoer, A. T.; Wei, K.; Helms, J. A.; Kuo, C. J.; Kraft, D. L.; Weissman, I. L. 2009 Endochondral ossification is required for haematopoietic stem-cell niche formation, Nature, 457, 490-41476-4687.

Cheung LK, Chua HDP, Hariri F, Lo J, Ow A, Zheng LW. Distraction osteogenesis. Oral and maxillofacial surgery, ed. Andersson L, Kahnberg KE, Pogrel MA, Wiley-Blackwell, 2010, chapter 48, pp. 1027-1059.

Cano J., campo J., Moreno L et al. Osteogenic alveolar distraction: A review of the literature. Oral Surg Oral Med Oral Pathol Orad <radiol Endod 101:11, 2006.

Dabirian N. and Rosén A. Implant treatment with or without bone grafting in resorbed edentulous maxillae: a two years follow-up study. Student thesis, Karolinska Institute, 2004.

Eriksen, E. F. 2010 Cellular mechanisms of bone remodeling, Rev Endocr Metab Disord, 11, 219-271573-2606.

Fang, T. D.; Nacamuli, R. P.; Song, H. M.; Fong, K. D.; Warren, S. M.; Salim, A.; Carano, R. A.; Filvaroff, E. H.; Longaker, M. T. 2004 Creation and characterization of a mouse model of mandibular distraction osteogenesis, Bone, 34, 1004-128756-3282.

Fedde, K. N.; Blair, L.; Silverstein, J.; Coburn, S. P.; Ryan, L. M.; Weinstein, R. S.; Waymire, K.; Narisawa, S.; Millan, J. L.; MacGregor, G. R.; Whyte, M. P. 1999 Alkaline phosphatase knock-out mice recapitulate the metabolic and skeletal defects of infantile hypophosphatasia, J Bone Miner Res, 14, 2015-260884-0431.

Giannoudis, P. V.; Dinopoulos, H.; Tsiridis, E. 2005 Bone substitutes: an update, Injury, 36 Suppl 3, S20-70020-1383.

Gordon, J. A.; Tye, C. E.; Sampaio, A. V.; Underhill, T. M.; Hunter, G. K.; Goldberg, H. A. 2007 Bone sialoprotein expression enhances osteoblast differentiation and matrix mineralization in vitro, Bone, 41, 462-738756-3282.

Gorski, J. P. 2011 Biomineralization of bone: a fresh view of the roles of non-collagenous proteins, Front Biosci, 17, 2598-6211093-4715.

Gorski, J. P.; Wang, A.; Lovitch, D.; Law, D.; Powell, K.; Midura, R. J. 2004 Extracellular bone acidic glycoprotein-75 defines condensed mesenchyme regions to be mineralized and localizes with bone sialoprotein during intramembranous bone formation, $J$ Biol Chem, 279, 25455-630021-9258. 
Harada, H.; Tagashira, S.; Fujiwara, M.; Ogawa, S.; Katsumata, T.; Yamaguchi, A.; Komori, T.; Nakatsuka, M. 1999 Cbfa1 isoforms exert functional differences in osteoblast differentiation, J Biol Chem, 274, 6972-80021-9258.

Huang, W.; Yang, S.; Shao, J.; Li, Y. P. 2007 Signaling and transcriptional regulation in osteoblast commitment and differentiation, Front Biosci, 12, 3068-921093-4715.

Huffman, N. T.; Keightley, J. A.; Chaoying, C.; Midura, R. J.; Lovitch, D.; Veno, P. A.; Dallas, S. L.; Gorski, J. P. 2007 Association of specific proteolytic processing of bone sialoprotein and bone acidic glycoprotein- 75 with mineralization within biomineralization foci, J Biol Chem, 282, 26002-130021-9258.

Janssens, K.; ten Dijke, P.; Janssens, S.; Van Hul, W. 2005 Transforming growth factor-beta1 to the bone, Endocr Rev, 26, 743-740163-769X.

Kahnberg KE. Treatment of bone deficient ridges in implant rehabilitation. Oral and maxillofacial surgery, ed. Andersson L, Kahnberg KE, Pogrel MA, Wiley-Blackwell, 2010, chapter 24, pp. 405-414.

Krekmanow L., Kahn M., Rangert B, et al. tilting of posterior mandibular and maxillary implants for improved prothesis support. Int J Oral Maxillofac Implants 15:405, 2000.

Kärner, E.; Backesjo, C. M.; Cedervall, J.; Sugars, R. V.; Ahrlund-Richter, L.; Wendel, M. 2009 Dynamics of gene expression during bone matrix formation in osteogenic cultures derived from human embryonic stem cells in vitro, Biochim Biophys Acta, 1790, 110 80006-3002.

Kärner, E.; Unger, C.; Sloan, A. J.; Ahrlund-Richter, L.; Sugars, R. V.; Wendel, M. 2007 Bone matrix formation in osteogenic cultures derived from human embryonic stem cells in vitro, Stem Cells Dev, 16, 39-521547-3287.

Karp, J. M.; Ferreira, L. S.; Khademhosseini, A.; Kwon, A. H.; Yeh, J.; Langer, R. S. 2006 Cultivation of human embryonic stem cells without the embryoid body step enhances osteogenesis in vitro, Stem Cells, 24, 835-431066-5099.

Koh, J. T.; Zhao, Z.; Wang, Z.; Lewis, I. S.; Krebsbach, P. H.; Franceschi, R. T. 2008 Combinatorial gene therapy with $\mathrm{BMP} 2 / 7$ enhances cranial bone regeneration, $J$ Dent Res, 87, 845-90022-0345.

Komori, T.; Yagi, H.; Nomura, S.; Yamaguchi, A.; Sasaki, K.; Deguchi, K.; Shimizu, Y.; Bronson, R. T.; Gao, Y. H.; Inada, M.; Sato, M.; Okamoto, R.; Kitamura, Y.; Yoshiki, S.; Kishimoto, T. 1997 Targeted disruption of Cbfa1 results in a complete lack of bone formation owing to maturational arrest of osteoblasts, Cell, 89, 755-6400928674.

Kong, Y. Y.; Feige, U.; Sarosi, I.; Bolon, B.; Tafuri, A.; Morony, S.; Capparelli, C.; Li, J.; Elliott, R.; McCabe, S.; Wong, T.; Campagnuolo, G.; Moran, E.; Bogoch, E. R.; Van, G.; Nguyen, L. T.; Ohashi, P. S.; Lacey, D. L.; Fish, E.; Boyle, W. J.; Penninger, J. M. 1999 Activated $\mathrm{T}$ cells regulate bone loss and joint destruction in adjuvant arthritis through osteoprotegerin ligand, Nature, 402, 304-90028-0836.

Kurata, K.; Heino, T. J.; Higaki, H.; Vaananen, H. K. 2006 Bone marrow cell differentiation induced by mechanically damaged osteocytes in 3D gel-embedded culture, J Bone Miner Res, 21, 616-250884-0431.

Kurt G., Altug-Atac AT., Atac MS., Karasu HA. Stability of surgically assisted rapid maxillary expansion and orthopedic maxillary expansion after 3 years follow-up. Angle orthodontist, 80;4:613-619, 2010. 
Leucht, P.; Kim, J. B.; Amasha, R.; James, A. W.; Girod, S.; Helms, J. A. 2008 Embryonic origin and Hox status determine progenitor cell fate during adult bone regeneration, Development, 135, 2845-540950-1991.

Marie, P. J. 2008 Transcription factors controlling osteoblastogenesis, Arch Biochem Biophys, 473, 98-1051096-0384.

Maiorana C. Biomaterials for bone replacement in implant surgery. Oral and maxillofacial surgery, ed. Andersson L, Kahnberg KE, Pogrel MA, Wiley-Blackwell, 2010, chapter 26, pp. 425-437.

Martin, E.; Shapiro, J. R. 2007 Osteogenesis imperfecta:epidemiology and pathophysiology, Curr Osteoporos Rep, 5, 91-71544-1873.

Mattson T., Köndell PÅ., Gynther G., et al. Implant treatment without bone grafting in severely resorbed edentulous maxillae. J Oral Maxillofac Surg 57:281, 1999.

Nakashima, K.; Zhou, X.; Kunkel, G.; Zhang, Z.; Deng, J. M.; Behringer, R. R.; de Crombrugghe, B. 2002 The novel zinc finger-containing transcription factor osterix is required for osteoblast differentiation and bone formation, Cell, 108, 17-2900928674.

Nesbitt, S. A.; Horton, M. A. 1997 Trafficking of matrix collagens through bone-resorbing osteoclasts, Science, 276, 266-90036-8075.

Nyström E., Ahlqvist J., Kahnberg KE. 10-years follow-up of onlay bone grafts and implants in severely resorbed maxillae. Int J Oral Maxillofac Surg 33:258, 2004.

Ramstad, V. E.; Franzen, A.; Heinegard, D.; Wendel, M.; Reinholt, F. P. 2003 Ultrastructural distribution of osteoadherin in rat bone shows a pattern similar to that of bone sialoprotein, Calcif Tissue Int, 72, 57-640171-967X.

Ripamonti, U.; Duneas, N.; Van Den Heever, B.; Bosch, C.; Crooks, J. 1997 Recombinant transforming growth factor-beta1 induces endochondral bone in the baboon and synergizes with recombinant osteogenic protein-1 (bone morphogenetic protein-7) to initiate rapid bone formation, J Bone Miner Res, 12, 1584-950884-0431.

Romberg, R. W.; Werness, P. G.; Riggs, B. L.; Mann, K. G. 1986 Inhibition of hydroxyapatite crystal growth by bone-specific and other calcium-binding proteins, Biochemistry, 25, 1176-800006-2960.

Rosén A., Gynther G. Implant treatment without bone grafting in severely resorbed edentulous maxillas: A long-term follow up study. J Oral Maxillofac Surg 65:10101016, 2007.

Rosén A., Modig M., Larson O. Orthognathic bimaxillary surgery in two patients with osteogenesis imperfecta and a review of the literature. Int J Oral Maxillofac Surg 2011, Aug; 40(8):866-73. Epub 2011 Apr 3.

Rosén A., Kruger Weiner C. Three years follow up of distraction osteogenesis treatment in two patient with frontal open bite and a review of the literature. In manuscript 2011.

Saulacic N., Zix J., lizuka T. Complication rates and associated factors in alveolar distraction osteogenesis: a comprehensive review. Int J Oral Maxillofac Surg 2009, 38(3):210-7. Epub 2009 Feb 14.

Schmid, P.; Cox, D.; Bilbe, G.; Maier, R.; McMaster, G. K. 1991 Differential expression of TGF beta 1, beta 2 and beta 3 genes during mouse embryogenesis, Development, 111, 117300950-1991. 
Si, X.; Jin, Y.; Yang, L. 1998 Induction of new bone by ceramic bovine bone with recombinant human bone morphogenetic protein 2 and transforming growth factor beta, Int $J$ Oral Maxillofac Surg, 27, 310-40901-5027.

Sugars, R. V.; Milan, A. M.; Brown, J. O.; Waddington, R. J.; Hall, R. C.; Embery, G. 2003 Molecular interaction of recombinant decorin and biglycan with type I collagen influences crystal growth, Connect Tissue Res, 44 Suppl 1, 189-950300-8207.

Sumner, D. R.; Turner, T. M.; Urban, R. M.; Virdi, A. S.; Inoue, N. 2006 Additive enhancement of implant fixation following combined treatment with rhTGF-beta2 and rhBMP-2 in a canine model, J Bone Joint Surg Am, 88, 806-170021-9355.

Takeda, S.; Bonnamy, J. P.; Owen, M. J.; Ducy, P.; Karsenty, G. 2001 Continuous expression of Cbfa1 in nonhypertrophic chondrocytes uncovers its ability to induce hypertrophic chondrocyte differentiation and partially rescues Cbfa1-deficient mice, Genes Dev, 15, 467-810890-9369.

Triplett, R. G.; Schow S. R.; Laskin D. M. 2000 Oral and maxillofacial surgery advances in implant dentistry, Int J Oral Maxillofac Surg 15(1), 47-55.

Tye, C. E.; Rattray, K. R.; Warner, K. J.; Gordon, J. A.; Sodek, J.; Hunter, G. K.; Goldberg, H. A. 2003 Delineation of the hydroxyapatite-nucleating domains of bone sialoprotein, J Biol Chem, 278, 7949-550021-9258.

Weiss, S.; Baumgart, R.; Jochum, M.; Strasburger, C. J.; Bidlingmaier, M. 2002 Systemic regulation of distraction osteogenesis: a cascade of biochemical factors, J Bone Miner Res, 17, 1280-90884-0431.

Wendel, M.; Sommarin, Y.; Heinegard, D. 1998 Bone matrix proteins: isolation and characterization of a novel cell-binding keratan sulfate proteoglycan (osteoadherin) from bovine bone, J Cell Biol, 141, 839-470021-9525.

Westendorf, J. J.; Kahler, R. A.; Schroeder, T. M. 2004 Wnt signaling in osteoblasts and bone diseases, Gene, 341, 19-390378-1119.

Wikesjsö, U.; Polimeni, G.; Xiropadidis, A.; Stravropoulos, A. Peridontal wound healing/regeneration; Quintessence: London, 2010.

Wozney, J. M.; Rosen, V.; Celeste, A. J.; Mitsock, L. M.; Whitters, M. J.; Kriz, R. W.; Hewick, R. M.; Wang, E. A. 1988 Novel regulators of bone formation: molecular clones and activities, Science, 242, 1528-340036-8075. 


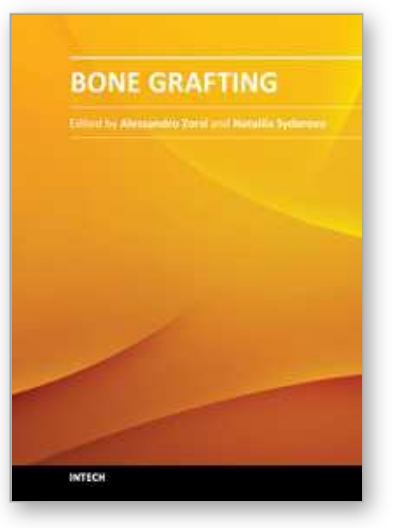

\author{
Bone Grafting \\ Edited by Dr Alessandro Zorzi
}

ISBN 978-953-51-0324-0

Hard cover, 214 pages

Publisher InTech

Published online 21, March, 2012

Published in print edition March, 2012

Bone grafting is the surgical procedure in which new bone (bone graft) or a replacement material (graft substitute), is placed into bone fractures or bone defects to aid in healing. Bone grafting is in the field of interest of many surgical specialties, such as: orthopedics, neurosurgery, dentistry, plastic surgery, head and neck surgery, otolaryngology and others. In common, all these specialties have to handle problems concerning the lack of bone tissue or impaired fracture healing. There is a myriad of surgical techniques nowadays involving some kind of bone graft or bone graft substitute. This book gathers authors from different continents, with different points of view and different experiences with bone grafting. Leading researchers of Asia, America and Europe have contributed as authors. In this book, the reader can find chapters from the ones on basic principles, devoted to students, to the ones on research results and description of new techniques, experts will find very beneficial.

\title{
How to reference
}

In order to correctly reference this scholarly work, feel free to copy and paste the following:

Annika Rosén and Rachael Sugars (2012). Clinical Concepts in Oral and Maxillofacial Surgery and Novel Findings to the Field of Bone Regeneration, Bone Grafting, Dr Alessandro Zorzi (Ed.), ISBN: 978-953-510324-0, InTech, Available from: http://www.intechopen.com/books/bone-grafting/clinical-concepts-in-oral-andmaxillofacial-surgery-and-novel-findings-to-the-field-of-bone-regenera

\section{INTECH}

open science | open minds

\section{InTech Europe}

University Campus STeP Ri

Slavka Krautzeka 83/A

51000 Rijeka, Croatia

Phone: +385 (51) 770447

Fax: +385 (51) 686166

www.intechopen.com

\section{InTech China}

Unit 405, Office Block, Hotel Equatorial Shanghai

No.65, Yan An Road (West), Shanghai, 200040, China

中国上海市延安西路65号上海国际贵都大饭店办公楼405单元

Phone: +86-21-62489820

Fax: $+86-21-62489821$ 
(C) 2012 The Author(s). Licensee IntechOpen. This is an open access article distributed under the terms of the Creative Commons Attribution 3.0 License, which permits unrestricted use, distribution, and reproduction in any medium, provided the original work is properly cited. 